\title{
Simulation and Experiments of Active Greenhouse Heating System
}

\author{
Yuanyuan Zhang, Xin Wang, Yibo Ma, Baoyan Xu, Dong Sun \\ Beijing Key Laboratory of Optimized Design for Modern Agricultural Equipment, \\ College of Engineering, China Agricultural University (East Campus), \\ Beijing, China \\ wangxin117@cau.edu.cn
}

\begin{abstract}
This paper proposed an active greenhouse heating system which focused on the problem of crop growth under extreme cold weather. At the beginning, heat transfer process of heating system was analysed based on thermal equilibrium theory. Radial and axial heat conduction mathematical analysis model of temperature control system were established respectively. Then, numerical simulation of temperature distribution was carried out by means of finite element method (FEM) software. When the effective operation range (later referred to as $Q_{\mathrm{f}}$ ) was defined with soil temperature more than $15{ }^{\circ} \mathrm{C}$ at $20 \mathrm{~cm}$ underground, opening temperature of heating system should be no less than $28{ }^{\circ} \mathrm{C}$. Simulation results show that an increase of air inlet temperature by $2{ }^{\circ} \mathrm{C}$ could extend axial effective operating range by $2.4 \mathrm{~m}-2.8 \mathrm{~m}$. Later, field test was implemented in greenhouses which located in Changping district, Beijing. Finally, compared with simulation data, the field testing data shows that the perturbation law of heating system heat transfer process on shallow and deep layer soil temperature is consistent with theoretical analysis. The numerical simulation could help to guide the temperature control of greenhouse.
\end{abstract}

Index Terms-Active greenhouse heating system; Temperature control effect; Heat transfer analysis; Numerical simulation; ANSYS.

\section{INTRODUCTION}

In recent years, greenhouse fruit and vegetable planting have faced a big problem which is greenhouse temperature control at winter night, especially extreme cold region [1], [2]. Under conditions of low temperature outdoor, simple structure and other factors, cold air enters the greenhouse in the form of heat conduction. This leads to indoor temperature out of control, which easily cause chilling injury and frost disaster [3]. Then greenhouse fruit and vegetable production will slash, which seriously bruise the enthusiasm for production of farmers [4]-[6]. Therefore, it becomes the key factor to ensure crops production in winter that how to effectively keep greenhouse soil thermal energy storage and soil temperature stable.

Greenhouse usually use hot blast stove, heating stove and other equipment to heat the air in winter at past. These methods make use of heat exchange effect between hot air and

Manuscript received 2 May, 2018; accepted 16 October, 2018.

This research was funded by grant (No. 2017YFD0700603 and No. 2017YFD0700603) the National Key Research and Development Program of China. soil to provide effective heat energy for soil, which establishes a suitable growth environment for crops [7]-[9]. However, high energy consumption equipment can not meet environmental standards, neither conform to the requirements of low carbon economic policies in China. As a new type devices for soil energy storage in winter, active heating system becomes more and more popular among greenhouse farmers [10]-[14]. Heating system is based on heat transfer theory and starts when daily temperature is high enough. Hot air is pumped in through air intake on one side of greenhouse by draught fan, then discharged by air outlet on the other side. Through heating pipe buried under the ground, hot air realized circulation. Heat transfer and energy storage process between hot air and soil can then be completed [15]-[20].

For the past few years, great progress has been made in the study of active greenhouse heating system. However, the research algorithm and simulation are slightly deficient in universality and not verified by experiments [21]-[24]. This paper focused on soil temperature control effect of active greenhouse heating system in cold environment. Firstly, the thermal physical properties of heating system was analysed in greenhouse environment. Then radial and axial heat transfer process of soil temperature field mathematical model was established based on thermal equilibrium theory. Further, numerical simulation and simulation analysis of system temperature field distribution was conducted by means of FEM software, which provided theoretical basis and computer aided design method for analysis method on the effect of temperature control. Finally, the validity and accuracy of analysis model was verified by field test.

\section{MAthematical Model FOR TemPerature CONTROL ANALYSIS}

It is the key issue of heat transfer process between hot air through heating pipe and soil for study on temperature control effect of active greenhouse heating system. Hot air in greenhouse is blew into heat exchange pipe of heating system by air intake vent, then discharged from air outlet after cooled by soil (Fig. 1). Heat exchange processes mainly include heat convection, heat conduction and thermal radiation. Heat convection and thermal radiation can be ignored under the internal condition of pipe, therefore, the main factors influencing soil energy storage is heat transfer process between heating pipes and soil. 


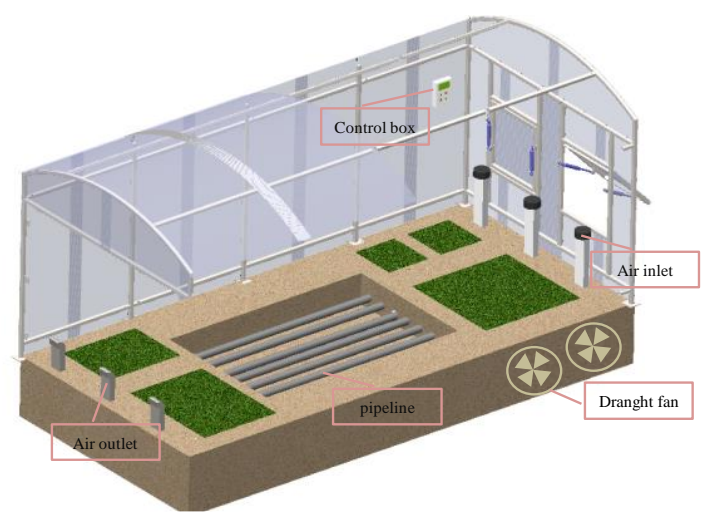

Fig. 1. Greenhouse heating system structure.

\section{A. Radial Heat Transfer Model}

In order to study on heat transfer process between heating pipes and soil, this paper analysed the influence of buried pipes for soil temperature distribution which used control volume method. As shown in Fig. 2, taking hot air transmitted by heating pipe as centre, the media around buried pipe in proper order are PE wall material, deep layer soil $T_{s}$ (under soil surface $\geq 20 \mathrm{~cm}$ ) and shallow layer soil $T_{a}$ (under soil surface $<20 \mathrm{~cm}$ ). Heat exchange exists between each layer. For analysed smoothly, following assumptions was made:

1. The factors which influenced soil temperature were neglected except cross-ventilation and heat exchange.

2. The soil thermal energy changed in gradient way along pipeline diameter to external.

3. Soil temperature of different layers kept uniform distribution in same section.

4. The temperature exchange of different layers can be equivalent to thermal resistance and heat capacity coupling model.

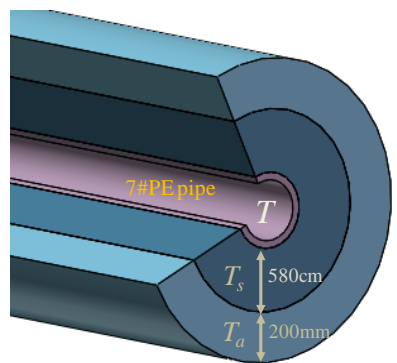

Fig. 2. Space diagram of radial temperature distribution in heating pipes.

As shown in Fig. 3, at $t+1$ of $i^{\text {th }}$ layer can be obtained by the instantaneous volume control equation

$T_{t+1, i}=\frac{\Delta \mathrm{t}}{\mathrm{C}_{i}}\left\lfloor Q_{i}+\frac{2\left(T_{t, i+1}-T_{t, \mathrm{i}}\right)}{R_{i+1}+R_{i}}+\frac{2\left(T_{t, i-1}-T_{t, i}\right)}{R_{i}+R_{i-1}}\right\rfloor+T_{t, i}$,

where $Q_{i}$ is heat source of $i^{\text {th }}$ layer, $\mathrm{C}_{i}$ is heat capacity of medium in different layer, $R_{i}$ is thermal resistance.

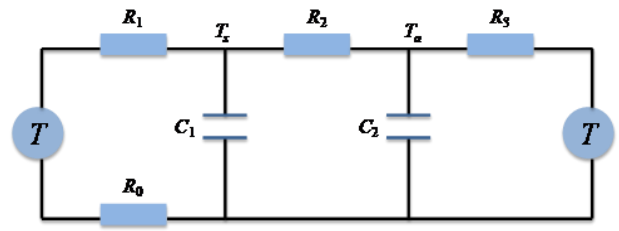

Fig. 3. The equivalent circuit diagram the heating pipe radial heat transfer process.

\section{B. Axial Heat Transfer Model}

The heat transfer model of active greenhouse heating system can be simplified as segmented one dimensional transient heat transfer model in axial direction. On basis of one dimensional finite element model, buried pipes was divided into $N$ segment along length direction. In addition, temperature distribution data of heating pipe was obtained by conducting energy analysis for each length, as shown in Fig. 4.

To simplify the model, following assumptions was made:

1. There were same thermal physical property parameters of hot air in the pipe, they were uniform such as temperature and humidity along the pipeline radial.

2. Heat transfer fluid was in-compressible Newtonian fluid, changes in rate of flow were ignored. Heat physical parameters didn't change over time in the process of heat exchange.

3. Initial soil temperature distribution was uniform, isotropic and thermal physical properties didn't change over time.

4. The influence on thermal physical properties of soil from environment temperature variation was ignored.

5 . The influence on thermal migration of soil moisture caused by heat transfer was ignored.

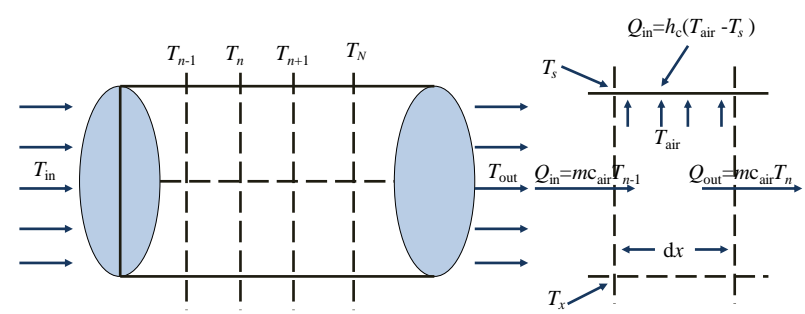

Fig. 4. Pipe section and heat balance diagram.

Based on the above assumptions, one dimensional heat transfer equation of heating system is established

$$
\dot{m} \text { caird } T x=A \mathrm{p} h \mathrm{c}\left(T_{s}-T_{x}\right) \mathrm{d} x,
$$

where $m$ is mass flow-rate $(\mathrm{kg} / \mathrm{s}), \mathrm{c}_{\text {air }}$ is specific heat of air fluid $(\mathrm{J} /(\mathrm{kg} \cdot \mathrm{K})), T_{x}$ is temperature along direction of pipeline $\left({ }^{\circ} \mathrm{C}\right), T_{s}$ is soil temperature $\left({ }^{\circ} \mathrm{C}\right), h_{\mathrm{c}}$ is pipe inwall thermal conductivity $(\mathrm{W} /(\mathrm{m} \cdot \mathrm{K})), x$ is distance from air intake vent $(\mathrm{m}), A_{\mathrm{p}}$ is pipe heat exchange area $\left(\mathrm{m}^{2}\right)$.

To each little segment, inlet air temperature is $T_{n-1}$, outlet air temperature is $T_{n}$. Assume that there will be no condensation for each unit volume in process of heat transfer, the average temperature formula of heat transfer is established

$$
T_{\text {air }}=\frac{\int_{0}^{\frac{L}{N}}\left[T_{s}-\left(T_{n-1}-T_{0}\right) \exp \left(-\frac{x}{\alpha}\right)\right] \mathrm{d} x}{\frac{L}{N}},
$$

where $L$ is pipe length (m), $N$ is section number of pipeline, $\alpha=\frac{m \mathrm{c}_{\text {air }}}{A_{\mathrm{p}} h_{\mathrm{c}}}$, which is soil temperature conductivity $\left(\mathrm{W} /\left(\mathrm{m} \cdot{ }^{\circ} \mathrm{C}\right)\right)$.

By this way, unit floor heating pipe outlet temperature can be acquired 


$$
T_{n}=T_{n-1}-\alpha\left\lfloor\frac{\int_{0}^{\frac{L}{N}}\left[T_{s}-\left(T_{n-1}-T_{0}\right) \exp \left(-\frac{x}{\alpha}\right)\right] \mathrm{d} x}{\frac{L}{N}}-T_{s}\right\rfloor
$$

\section{COMPUTER AIDED CALCULATION AND ANALYSIS}

In order to numerically analyse the effect of active greenhouse heating system on soil heat storage, this paper used ANSYS software to do simulation work. ANSYS thermal analysis module bases on heat balance equations derived by principle of conservation of energy, mainly involves steady-state analysis, transient analysis, thermal radiation, phase change, thermal stress and coupling field analysis related heat. Based on the simplified model, radial and axial temperature distribution of heating pipe were analysed respectively.

\section{A. Radial Heat Transfer Temperature Field Analysis}

This paper adopted PLANE55 axisymmetric element for two-dimensional heat conduction analysis which consisted of four nodes. Assuming that each node is only with one temperature degree of freedom, which is suitable for heat conduction steady-state and transient analysis. These conditions meet the requirements of heat flow transmission when hot air is with constant flow speed. According to actual characteristics of greenhouse soil thermal physical property, the soil is divided into shallow layer soil (apart from the ground $0 \mathrm{~m}-0.2 \mathrm{~m}$ ) and deep layer soil (apart from the ground $0.2 \mathrm{~m}-6 \mathrm{~m}$ ), then separately made property definitions. Thermal physical property parameters are shown in Table I.

TABLE. I. CALCULATION MODEL THERMAL PARAMETERS

\begin{tabular}{|c|c|c|c|}
\hline Model & $\begin{array}{c}\text { Density } \\
(\mathbf{K g} \cdot \mathbf{m}-\mathbf{3})\end{array}$ & $\begin{array}{c}\text { Specific heat } \\
\mathbf{c p}(\mathbf{J} \cdot \mathbf{K g}-\mathbf{1} \cdot \mathbf{K}-\mathbf{1})\end{array}$ & $\begin{array}{c}\text { Heat } \\
\text { conductivity } \\
(\mathbf{W} \cdot \mathbf{m}-\mathbf{1} \cdot \mathbf{K}-\mathbf{1})\end{array}$ \\
\hline Air & 1.225 & 1006 & 0.0242 \\
\hline Shallow layer soil & 1500 & 1390 & 1.12 \\
\hline Deep layer soil & 2050 & 1450 & 2.40 \\
\hline PE pipe & 940 & 1000 & 0.50 \\
\hline
\end{tabular}

According to the structural characteristics of system, meshing near heating pipe was mapped. Size of grid gradually enlarged from centre to surrounding in order to improve calculation accuracy and computation efficiency. The analysis model temperature radial distribution and the grid meshing are shown in Fig. 5.

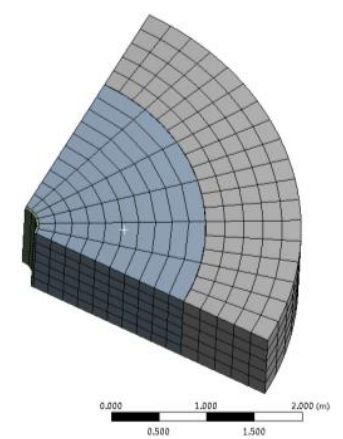

Fig. 5. Radial temperature distribution meshing.

Based on previous test data, climate in greenhouse at winter from 9 o'clock to 12 o'clock were simulated. Outlet temperature of heating system was set as the initial temperature of pipe heat source to load. On the assumption that soil temperature at $4 \mathrm{~m}$ underground is $14{ }^{\circ} \mathrm{C}$ and soil surface temperature is $6^{\circ} \mathrm{C}$, winter heat exchange amount was simulated accordance with $40 \mathrm{~W} / \mathrm{m}$. When $T_{\text {in }}=24{ }^{\circ} \mathrm{C}, 26^{\circ} \mathrm{C}$, $28{ }^{\circ} \mathrm{C}, 30{ }^{\circ} \mathrm{C}$ severally, three-dimensional radial steady temperatures distribution of heating system is shown in Fig. 6.

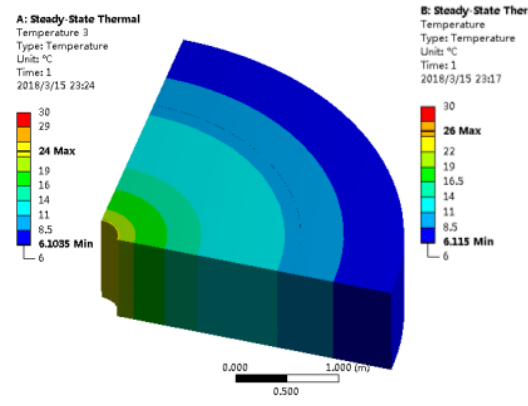

(a)

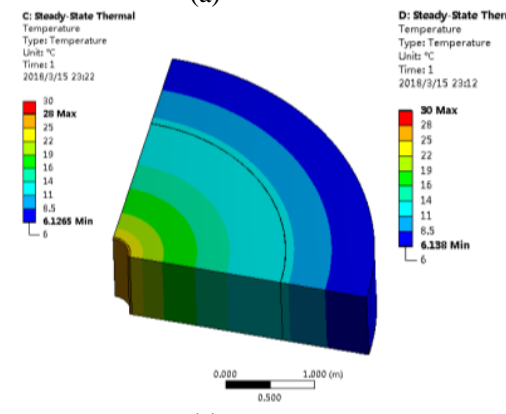

(c)

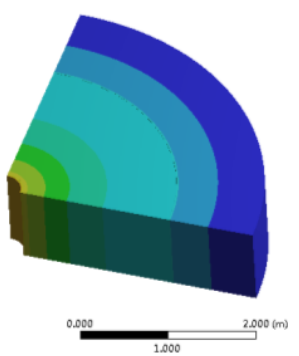

(b)

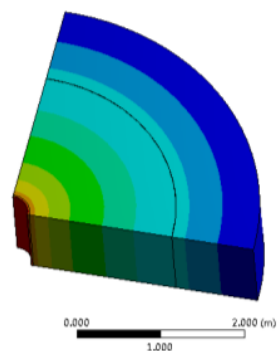

(d)
Fig. 6. Heating system radial temperature distribution results: (a) $T_{\text {in }}=$ $24{ }^{\circ} \mathrm{C}$; (b) $T_{\text {in }}=26{ }^{\circ} \mathrm{C}$; (c) $T_{\text {in }}=28{ }^{\circ} \mathrm{C}$; (d) $T_{\text {in }}=30{ }^{\circ} \mathrm{C}$.

Results of pipe heat transfer in terms of heat balance indicated that heating scope usually can not reach to soil surface when temperature of hot air keeps constantly in heat pipe. In other words, scope of soil heating range usually can not radiate to shallow soil because of the existence of convection between soil surface and hot air. Crop root system normally distribute in the area at $20 \mathrm{~cm}-25 \mathrm{~cm}$ underground where soil temperature is advisable by $15^{\circ} \mathrm{C}-18{ }^{\circ} \mathrm{C}$ in winter. Therefore, if considering the area at $20 \mathrm{~cm}$ underground where temperature rise is greater than $15{ }^{\circ} \mathrm{C}$ as effective operation range, analysis results in Fig. 6(c) and Fig. 6(d) meet $Q_{\mathrm{f}}$ index requirements. However, in Fig. 6(a) and Fig. 6(b), it still can not effectively increase soil temperature near crop root system after reaching heat balance due to less thermal energy provided by hot air. Thus, it also can't reach the purpose of promoting crop growth.

\section{B. Axial Temperature Distribution}

The effect to soil thermal storage can be more intuitively understood by means of undergoing two-dimension steady state heat transfer analysis along heating pipe axial direction. The FEM unit type selected in this analysis is same as radial temperature distribution, meshing model shows in Fig. 7.

The air intake inhaled hot air at work time, and outlet discharged cold air after heat transfer, then convection was formed within greenhouse. Therefore, soil surface temperature loading formula can be written as follows

$$
y=-0.1 x+10(0 \leq x \leq 40),
$$


where $x$ is the distance from air intake vent (m), $y$ is loading temperature $\left({ }^{\circ} \mathrm{C}\right)$.

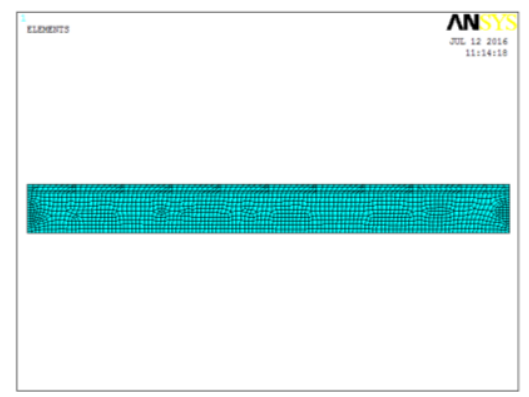

Fig. 7. Axial temperature distribution meshing.

Due to heat transfer in pipeline, the axial loading formula is written as follows

$$
y=-0.175 x+27(0 \leq x \leq 40) .
$$

The soil temperature at $4 \mathrm{~m}$ underground was assumed as $14{ }^{\circ} \mathrm{C}$ which belong to the scope without disturbance. Winter heat exchange amount was simulated accordance with the $40 \mathrm{~W} / \mathrm{m}$, and the temperature of air intake was set as $28^{\circ} \mathrm{C}$. axial transmission range was $40 \mathrm{~m}$ according to actual laying situation of ground heating. Two-dimensional axial steady temperature distribution of heat system is shown in Fig. 8.

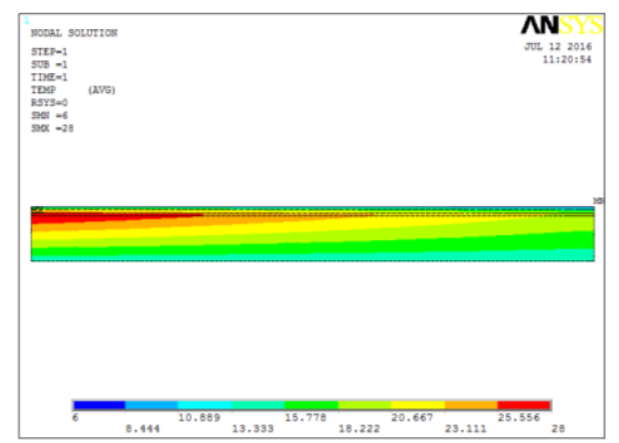

Fig. 8. Heating system axial temperature distribution results.

Analysis results indicated that temperature rise radiation scope of heating system gradually reduced along pipeline axial direction, the point $x=22.67 \mathrm{~m}$ met $Q_{\mathrm{f}}$ index in Fig. 8. In other words, the heating effect of pipe for soil weakened gradually along axial direction because of heat exchange function between hot air and soil. Heating effect received by soil became weaker when air intake was installed at the side of the greenhouse. In order to further study the effective working range of heating system along axial direction, set inlet temperature of hot air as $T_{\text {in }}$ for two-dimension steady state thermal analysis, whose values were $24{ }^{\circ} \mathrm{C}, 26{ }^{\circ} \mathrm{C}, 28{ }^{\circ} \mathrm{C}$ and $30{ }^{\circ} \mathrm{C}$, selected $x=15 \mathrm{~m}-25 \mathrm{~m}$ as temperature field local zoom range. The specific analysis results are shown in Fig. 9.

Comparing axial analysis results, we can see that it is similar to radial analysis results. If air intake vent temperature is too low such as $T_{\text {in }}=24{ }^{\circ} \mathrm{C}$, heat energy carried by hot air is little, so it is difficult to achieve the purpose of heating soil surrounding crop root system. With the temperature of air intake vent increasing, radial radiation range of system increased gradually which meet $Q_{\mathrm{f}}$ index requirement, an increase in hot air temperature by $2{ }^{\circ} \mathrm{C}$ extended axial effective operating radiation range by $2.4 \mathrm{~m}-2.8 \mathrm{~m}$. The greenhouse air temperature rise is limited in winter, and range of heating pipe is only $40 \mathrm{~m}$ which is not able to have effective heating effect in distal.

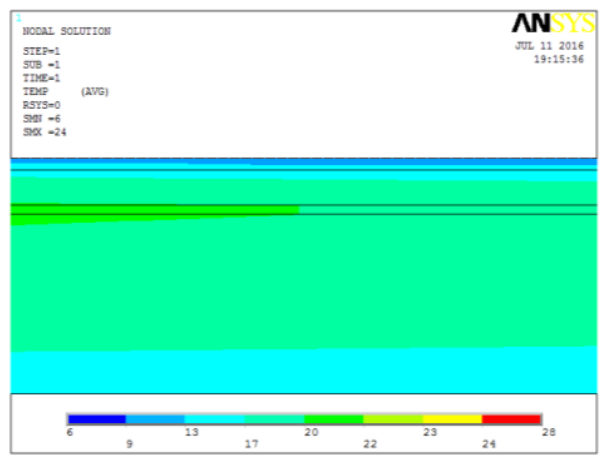

(a)

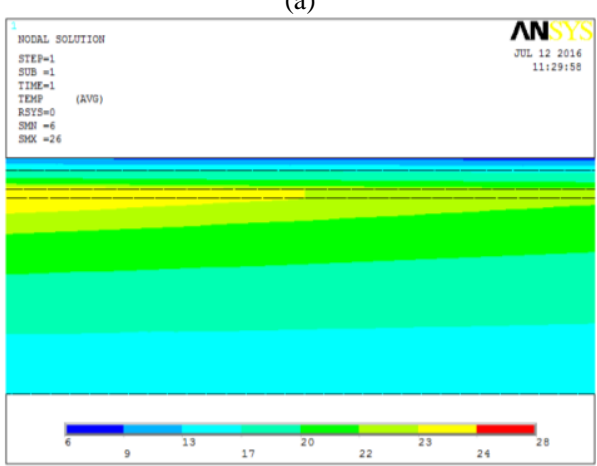

(b)

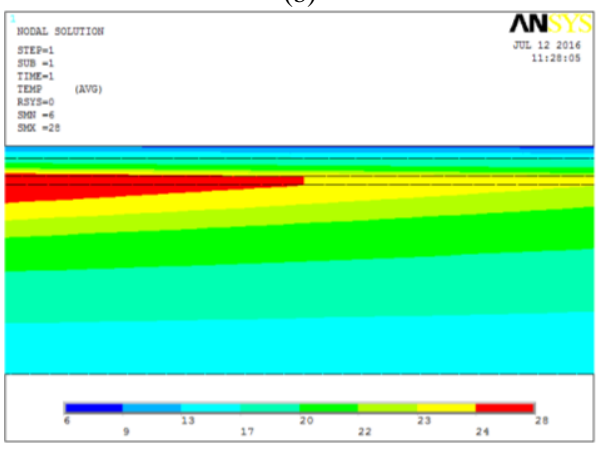

(c)

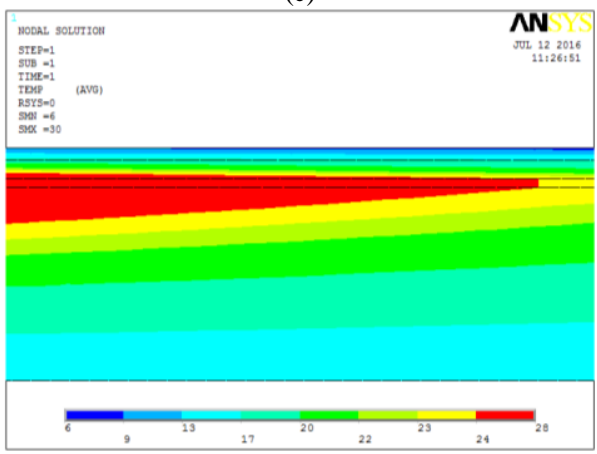

(d)

Fig. 9. Heating system partially enlarged axial temperature distribution $(x=$ $15 \mathrm{~m}-25 \mathrm{~m}$ ) results: (a) $T_{\text {in }}=24^{\circ} \mathrm{C}$; (b) $T_{\text {in }}=26{ }^{\circ} \mathrm{C}$; (c) $T_{\text {in }}=28{ }^{\circ} \mathrm{C}$; (d) $T_{\text {in }}=$ $30{ }^{\circ} \mathrm{C}$.

\section{GREENHOUSE VERIFY EXPERIMENT}

In winter, heating system temperature rise effect assessment was conducted to test in crop variety test show base within number 25 greenhouse located in Ma Chi Kou town, Changping district, Beijing. The test adopted multi-point temperature and humidity data acquisition remote monitoring system made by laboratory (system physical 
structure is shown in Fig. 10), which continuously collected greenhouse and outdoor temperature data for 4 months a total of 122 days (since December 2015 to March 2016). Measurement and control system working voltage was $12 \mathrm{~V}$, sampling period was one hour, temperature acquisition precision was $\pm 0.2{ }^{\circ} \mathrm{C}$, temperature detection range was $-40{ }^{\circ} \mathrm{C}-60{ }^{\circ} \mathrm{C}$, humidity acquisition precision was $\pm 0.3 \%$, humidity monitoring scope was $0 \%-100 \%$.

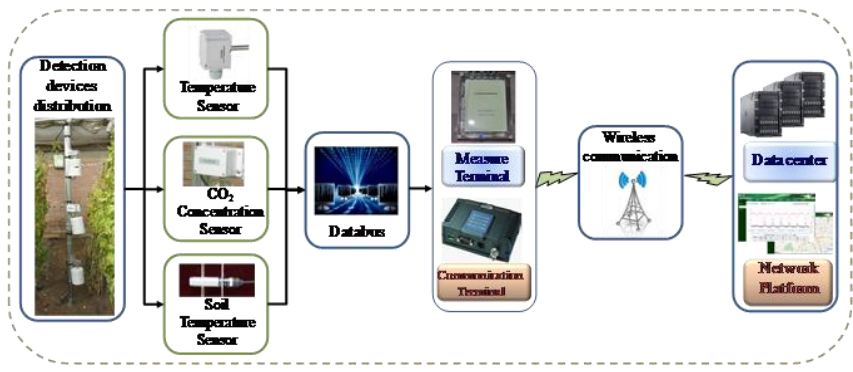

Fig. 10. Physical structure diagram of effect test.

The temperature measurement scheme of heating system temperature control effect experiment was formulated on basis of 'Sunlight greenhouse and plastic canopy structure and performance requirements'. The soil and air temperature sensor is used to detect relative temperature parameters, data transmission through bus to the system control box which was installed on the wall side of greenhouse. According to the current data value, control system opens or closes heating system and sends out control instructions. The remote network platform is used to analyse and deal with collecting data which transmitted through the GPRS wireless. The installation of detectors diagram is shown in Fig. 11.

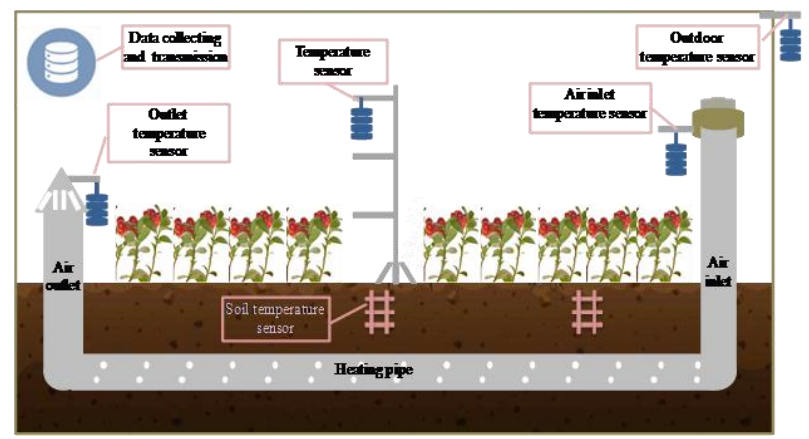

Fig. 11. Sensors installation diagram of temperature testing system.

Data acquisition system made a real-time monitoring respectively for outdoor air temperature, heating system air inlet temperature, air outlet temperature, air temperature in the central part of greenhouse (divided into air of high layer (150 $\mathrm{cm}$ away from the ground), middle layer (100 cm away from the ground), low layer (50 cm away from the ground)) and soil temperature in the central part of greenhouse (divided into soil of high layer(at $10 \mathrm{~cm}$ underground), middle layer (at $20 \mathrm{~cm}$ underground), low layer (at $30 \mathrm{~cm}$ underground). The wireless network is used for sending detected data back to remote monitoring platform, the monitoring data curve and historical data interface are shown in Fig. 12(a) and Fig. 12(b) respectively.

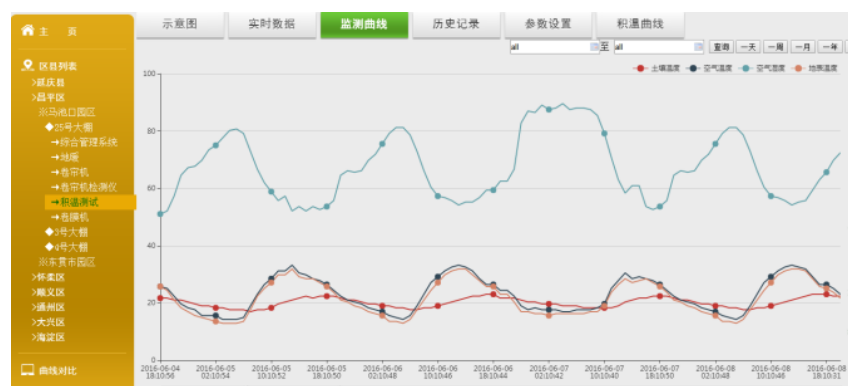

(a)

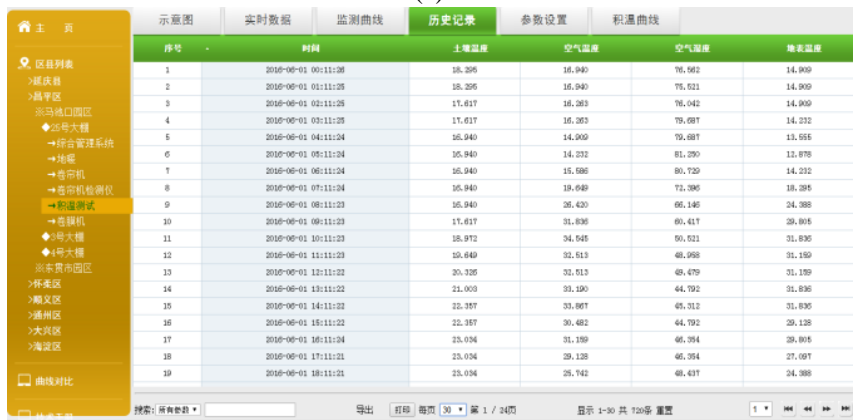

(b)

Fig. 12. Remote data monitoring pages: (a) data curve; (b) historical data table.

It is the main function of greenhouse heating system that using the heating effect of daytime light for air to achieve heating soil by means of leading hot air into heating pipe on cold weather condition in cold region. Therefore, select the date when the average temperature is below $0{ }^{\circ} \mathrm{C}$ as sample data of heating system temperature control effect to analyse impact on soil temperature rise effect on the condition that heating system was opening or closing (sample data are shown in Table II, because of the large amount of data, only selected sample data on January 10, 11, 2016, at 9 to 16 o'clock for instance).

In order to analyse sample data, the following evaluation indexed were assumed for heating system. $\Delta \mathrm{T}$ was regarded as temperature difference value between air inlet and outlet. $\Delta \mathrm{T}_{10 \mathrm{~cm}}$ was regarded as soil temperature rise away from ground $10 \mathrm{~cm} . \Delta \mathrm{T}_{20 \mathrm{~cm}}$ was regarded as soil temperature rise away from ground $20 \mathrm{~cm}$.

$\Delta \mathrm{T}$ and $\Delta \mathrm{T}_{20 \mathrm{~cm}}$ these two indexes were conducted a contrast analysis in Fig. 13(a). In the sample day from 15 o'clock to16 o'clock, air intake vent temperature ranged from $15^{\circ} \mathrm{C}$ to $18{ }^{\circ} \mathrm{C}$, air outlet temperature ranged from $12{ }^{\circ} \mathrm{C}$ to $15^{\circ} \mathrm{C}$. $\Delta \mathrm{T}$ was no more than $3{ }^{\circ} \mathrm{C}$ in this time, heat energy inside heating pipe was lower. Regardless of the switch state of heating system, all the changes of $\Delta \mathrm{T}_{20 \mathrm{~cm}}$ were a bit little, finally unable to realize heating effect for soil around crop effectively grown. The test results were similar to analysis of FEM simulation. It analysed the impact of heating system state on soil temperature rise in Fig. 13(b) when $\Delta \mathrm{T}$ gradually increased. The result indicated that $\Delta \mathrm{T}_{20 \mathrm{~cm}}$ index increased significantly when $\Delta \mathrm{T}$ is greater than $6{ }^{\circ} \mathrm{C}$. On the contrary, soil temperature rise effect decreased significantly when heating system was closed, but there was no obvious relationship with shallow soil temperature $\Delta \mathrm{T}_{10 \mathrm{~cm}}$. This conclusion was consistent with the results of two-dimensional radial steady temperature distribution. 
TABLE II. SAMPLE DATE DAILY AVERAGE TEMPERATURE BELOW $0^{\circ} \mathrm{C}$ COLLECT DATA INSTANCE.

\begin{tabular}{|c|c|c|c|c|c|c|c|c|}
\hline Date & Hour & $\begin{array}{l}\text { Switch } \\
\text { state }\end{array}$ & $\begin{array}{c}\text { Outdoor } \\
\text { temperature }\left({ }^{\circ} \mathbf{C}\right)\end{array}$ & $\begin{array}{c}\text { Average daily } \\
\text { temperature } \\
\left({ }^{\circ} \mathrm{C}\right) \\
\end{array}$ & $\begin{array}{c}\text { Inlet } \\
\text { temperature } \\
\left({ }^{\circ} \mathbf{C}\right)\end{array}$ & $\begin{array}{c}\text { Outlet } \\
\text { temperature } \\
\left({ }^{\circ} \mathbf{C}\right) \\
\end{array}$ & $\begin{array}{c}\text { Soil temperature } \\
\qquad \Delta \mathbf{T}_{\mathbf{2 0 \mathrm { cm }}}\left({ }^{\circ} \mathbf{C}\right)\end{array}$ & $\begin{array}{c}\text { Soil } \\
\text { temperature } \\
\Delta \mathrm{T}_{10 \mathrm{~cm}}\left({ }^{\circ} \mathrm{C}\right)\end{array}$ \\
\hline \multirow{7}{*}{ 2016-1-10 } & 09 & close & -4.18 & \multirow{7}{*}{-5.32} & 13.96 & 4.21 & 2.72 & 3.75 \\
\hline & 10 & open & -4.73 & & 16.67 & 6.65 & 2.72 & 4.43 \\
\hline & 11 & open & -4.18 & & 23.78 & 12.47 & 3.40 & 5.11 \\
\hline & 12 & open & -5.88 & & 25.34 & 15.11 & 4.08 & 6.46 \\
\hline & 14 & open & -5.00 & & 19.45 & 16.60 & 6.11 & 7.17 \\
\hline & 15 & open & -6.89 & & 17.14 & 16.20 & 6.78 & 7.52 \\
\hline & 16 & open & -6.55 & & 11.52 & 10.17 & 7.46 & 10.17 \\
\hline \multirow{7}{*}{ 2016-1-11 } & 09 & close & -0.93 & \multirow{7}{*}{-1.94} & 8.68 & 2.38 & 3.40 & 4.75 \\
\hline & 10 & close & -4.66 & & 9.83 & 4.08 & 3.40 & 4.75 \\
\hline & 11 & open & -2.15 & & 12.34 & 4.69 & 3.40 & 4.75 \\
\hline & 13 & open & -1.00 & & 24.86 & 17.08 & 4.75 & 6.78 \\
\hline & 14 & open & -1.81 & & 20.05 & 15.32 & 6.11 & 7.46 \\
\hline & 15 & open & -2.15 & & 18.16 & 15.18 & 6.78 & 8.82 \\
\hline & 16 & open & -2.02 & & 12.07 & 10.30 & 6.78 & 8.82 \\
\hline
\end{tabular}

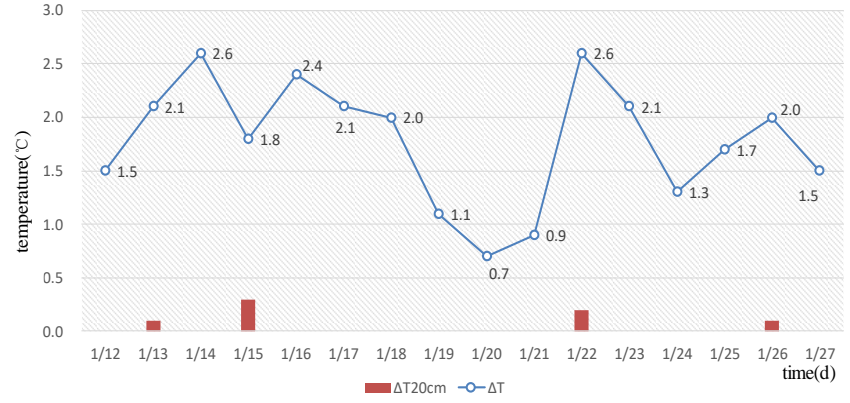

(a)

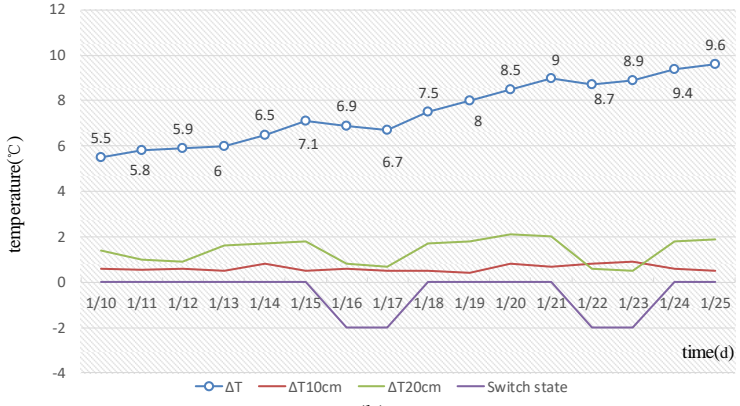

(b)

Fig. 13. Heating system test sample data: (a) Temperature acquisition results of heating system at 15 o'clock-16 o'clock in sample day; (b) Temperature acquisition results of heating system at 12 o'clock-13 o'clock in sample day. Here, the value of yellow line is equal to 0 to indicate the opening of heating system, and -2 represents switch.

\section{CONCLUSIONS}

1. Under conditions, that hot air inside pipe constantly load and radial thermal energy of heating system reach thermal equilibrium, temperature distribution effect indicated that heating range of pipe was limited. It met demand on $Q_{\mathrm{f}}$ index when air temperature inside pipe was greater than $28{ }^{\circ} \mathrm{C}$ and realized effective operation of heating system. In consequence, open temperature of heating system can be set up according to the conclusion.

2. Temperature rise effect of heating system worn off along axial direction of pipeline, the radiation scope was limited. Air inlet and outlet of system respectively installed on both sides in greenhouse, unable to realize the whole warming effect of greenhouse soil. The heating range of unilateral type of air supply structure was limited along axial distribution of heating pipeline. Therefore, it was necessary to further consider optimizing the structure of heating system for improving running effect.

3 . Filed test further verified the validity of numerical analysis model. Installation structure of active heating system can be analysed by using this model, which provides a theoretical basic for structural improvement. Yet validation test results were slightly lower than temperature simulation analysis, this was mainly due to thermal analysis model without considering lost heat when soil abstract heat outside greenhouse.

4. Taking advantage of active greenhouse heating system can effectively improve shallow soil temperature and promote crop root to grow. Heating effect is obvious when $\Delta \mathrm{T}$ is greater than $6^{\circ} \mathrm{C}$. The inlet temperature can be set according to this value in practical application.

5. There are high university and reliability of parameter detection scheme and data storage platform, which is also applicable to the inspection of active heating system after structural adjustment.

\section{REFERENCES}

[1] F. R. Mazarron, C. J. Porras-Prieto, J. L. Garcia, R. M. Benavente, "Feasibility of active solar water heating systems with evacuated tube collector at different operational water temperatures", Energy Conversion and Management, vol. 113, pp. 16-26, 2016. DOI: 10.1016/j.enconman.2016.01.046.

[2] B. Zhang, X. Fan, M. Liu, W. Hao, "Experimental study of the burning-cave hot water soil heating system in solar greenhouse", Renewable Energy, vol. 87, pp. 1113-1120, 2016. DOI: 10.1016/j.renene.2015.08.020.

[3] S. Du, Y. Li, C. Ma, Q. Chen, W. Yang, "Current situation on greenhouse environment control system modes in China", Trans. Chinese Society of Agricultural Engineering, vol. 20, no. 1, pp. 7-12, 2004. DOI: 10.3321/j.issn:1002-6819.2004.01.002.

[4] Y. Bi, S. Ma, "Research on current situation and development of environment control system modes i greenhouse in China", Journal of 
Agricultural Mechanization Research, 2009. DOI: 10.3969/j.issn.1003-188X.2009.03.070.

[5] Y. K. Bai, W. H. Liu, T. L. Wang, G. H. Tong, S. C. Meng, "Experimental research on environment and heat preservation effect of solar greenhouse. type Liaoshen I", Trans. Chinese Society of Agricultural Engineering, vol. 19, no. 5, pp. 191-196, 2003. DOI: 10.3321/j.issn:1002-6819.2003. 05.038.

[6] R. Malekian, D. C. Bogatinoska, A. Karadimce, N. Ye, J. Trengoska, W. A. Nyako, "A novel smart ECO model for energy consumption optimization", Elektronika ir Elektrotechnika, vol. 21, no. 6, 2015. DOI: 10.5755/ j01.eee.21.6.13771.

[7] H. Y. Lei, W. Y. Li, "Heat storage technique of geothermal greenhouse", Trans. Chinese Society for Agricultural Machinery, vol. 36, no. 9, pp. 83-85, 2005. DOI 10.3969/j.issn.1000-1298.2005.09.022.

[8] J. Q. Yu, "Progress in protected vegetable production and research during 'The Eleventh Five-year Plan' in China”, China Vegetables, no. 2, pp. 11-23, 2011.

[9] T. CH. Wang, "Report on application of solar greenhouse in Beijing suburb", Agricultural Engineering Technology (Greenhouse and Horticulture), no. 1, pp. 13-15, 2009.

[10] A. Bascetincelik, H. H. Ozturk, H. O. Paksoy, Y. Demirel, "Energetic and exergetic efficiency of latent heat storage system for greenhouse heating", Renewable Energy, vol. 16, no. 1-4, pp. 691-694, 1999. DOI: $10.1016 / \mathrm{S} 0960-1481(98) 00253-5$.

[11] W. M. Ding, X. Y. Wang, Y. N. Li, J. Wang, "Review on environmental control and simulation models for greenhouses", Trans. Chinese Society for Agricultural Machinery, no. 5, vol. 40, pp. 162-168, 2009.

[12] O. Ozgener, A. Hepbasli, "Exergoeconomic analysis of a solar assisted ground-source heat pump greenhouse heating system", Applied Thermal Engineering, vol. 25, no. 10, pp. 1459-1471, 2005. DOI: 10.1016/j.applthermaleng.2004.09.015.

[13] H. P. Mao, X. N. Wang, D. H. Wang, "The design and test of greenhouse solar energy heating system", Acta Energiae Solaris Sinica, no. 3, vol. 25, pp. 305-309, 2004. DOI: 10.3321/j.issn:0254-0096.2004.03.007.

[14] M. Esen, T. Yuksel, "Experimental evaluation of using various renewable energy sources for heating a greenhouse", Energy and Buildings, vol. 65, pp. 340-351, 2013.
DOI: 10.1016/j.enbuild.2013.06.018

[15] SH. X. Wang, CH. SH. Ma, J. Zhang, C.H. Zhao, G. Qin, "Substrate heating system with solar energy for greenhouse", Trans. CSAE, no. 5 , vol. 19, pp. 197-203, 2003. DOI 10.3321/j.issn:1002-6819.2003.05.039.

[16] J. Siroky, F. Oldewurtel, J. Cigler, S. Privara, "Experimental analysis of model predictive control for an energy efficient building heating system", Applied Energy, vol. 88, no. 9, pp. 3079-3087, 2011. DOI 10.1016/j.apenergy.2011.03.009.

[17] Y. W. Wang, X. W. Miao, SH. R. Cui, X. F. Liang, "Study on the heat storing and heating performances of an underground heat storage system in greenhouse", Trans. Chinese Society for Agricultural Machinery, no. 1, vol. 36, pp. 75-79, 2005. DOI: 10.3969/j.issn.1000-1298.2005.01.021.

[18] P. Mcmahon, "Control panel for greenhouse environment control computer", Computer, 2006.

[19] V. P. Sethi, K. Sumathy, C. Lee, D. S. Pal, "Thermal modeling aspects of solar greenhouse microclimate control: A review on heating technologies", Solar Energy, no. 4, vol. 96, pp. 56-82, 2013. DOI: 10.1016/j.solener.2013.06.034

[20] Q. L. Dai, R. Zuo, P. Li, ZH. Q. Zhang, W. J. Su, "Active solar heating system with soil heat storage for plastic film greenhouse and its effects", Trans. CSAE, no. 7, pp. 164-168, 2009. DOI: 10.3969/j.issn.1002-6819.2009.07.030.

[21] V. Markevicius, D. Navikas, D. Andriukaitis, M. Cepenas, A Valinevicius, M. Zilys, R. Malekian, A. Janeliauskas, W. Walendziuk, A. Idzkowski, "Two thermocouples low power wireless sensors network", AEU - International Journal of Electronics and Communications, vol. 84, pp. 242-250, 2018. DOI: 10.1016/j.aeue.2017.11.032.

[22] G. Russo, A. S. Anifantis, G. Verdiani, "Environmental analysis of geothermal heat pump and LPG greenhouse heating systems", Biosystems Engineering, no. 127, pp. 11-23, 2014. DOI: 10.3969/j.issn.1002-6819.2009.07.030.

[23] Q. Jiang, J. H. Li, J. B. Mei, "Transient simulation of the air-earth heat transfer in greenhouse", Acta Energiae Solaris Sinica, no. 2, pp. 227-232, 2002. DOI: 10.1016/j.biosystemseng.2014.08.002.

[24] CH. H. Xia, X. Zhou, Q. Ouyang, Y. X. Zhu, "Numerical simulation and analysis of underground duct system", Acta Energiae Solaris Sinica, no. 9, pp. 923-928, 2006. 